\title{
Development of Gold Standard Ion-Selective Electrode-Based Methods for Fluoride Analysis
}

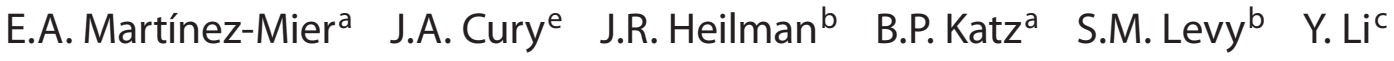 \\ A. Maguire $^{f} \quad$ J. Margineda ${ }^{\text {h }}$ D. O'Mullane ${ }^{i}$ P. Phantumvanit ${ }^{j} \quad$ A.E. Soto-Rojas ${ }^{a}$ \\ G.K. Stookey $^{a}$ A. Villak J.S. Wefel ${ }^{b}$ H. Whelton ${ }^{i}$ G.M. Whitford ${ }^{d}$ D.T. Zero ${ }^{a}$ \\ W. Zhang ${ }^{c}$ V. Zohourig \\ a Indiana University School of Dentistry, Indianapolis, Ind., b University of lowa, lowa City, lowa, \\ 'Loma Linda University, Loma Linda, Calif., and d Medical College of Georgia, Augusta, Ga., USA; \\ e University of Campinas, UNICAMP, Campinas, Brazil, ${ }^{f}$ University of Newcastle upon Tyne, Newcastle upon Tyne, \\ and ${ }^{9}$ Teesside University, Middlesbrough, UK; ${ }^{h}$ Roche Diagnostics, Barcelona, Spain; 'University Dental School, \\ Cork, Ireland; ${ }^{\text {T}}$ Thammasat University, Bangkok, Thailand; ${ }^{k}$ Universidad de Chile, Santiago, Chile
}

\section{Key Words}

Fluoride $\cdot$ Fluoride analysis • Fluoride ion-selective

electrode $\cdot$ Public dental health $\cdot$ Validity

\begin{abstract}
Background/Aims: Currently available techniques for fluoride analysis are not standardized. Therefore, this study was designed to develop standardized methods for analyzing fluoride in biological and nonbiological samples used for dental research. Methods: A group of nine laboratories analyzed a set of standardized samples for fluoride concentration using their own methods. The group then reviewed existing analytical techniques for fluoride analysis, identified inconsistencies in the use of these techniques and conducted testing to resolve differences. Based on the results of the testing undertaken to define the best approaches for the analysis, the group developed recommendations for direct and microdiffusion methods using the fluoride ion-selective electrode. Results: Initial results demonstrated that there was no consensus regarding the choice of analytical techniques for different types of samples. Although for several
\end{abstract}

types of samples, the results of the fluoride analyses were similar among some laboratories, greater differences were observed for saliva, food and beverage samples. In spite of these initial differences, precise and true values of fluoride concentration, as well as smaller differences between laboratories, were obtained once the standardized methodologies were used. Intraclass correlation coefficients ranged from 0.90 to 0.93 , for the analysis of a certified reference material, using the standardized methodologies. Conclusion: The results of this study demonstrate that the development and use of standardized protocols for $F$ analysis significantly decreased differences among laboratories and resulted in more precise and true values. Copyright $\odot 2010$ S. Karger AG, Basel

In the last century, fluoride (F) analysis has evolved from simple colorimetric analysis, which yielded crude results and suffered from interference from other ions present in the samples, to more complex methods of analysis such as mass spectrometry, gas chromatography, ion chromatography, electroanalysis, catalytic-enzymat-

\section{KARGER}

(C) 2010 S. Karger AG, Basel

Fax +41613061234 E-Mail karger@karger.ch www.karger.com www.karger.com/cre
Dr. E. Angeles Martínez-Mier, DDS, MSD, PhD

Preventive and Community Dentistry

Oral Health Research Institute, Indiana University School of Dentistry

415 Lansing Street, Indianapolis, IN 46202 (USA)

Tel. +1 317274 8822, Fax +1 317274 5425, E-Mail esmartin@iupui.edu 
ic and radioanalytical methods [Venkateswarlu, 1990]. Rapid development in the F analysis field has occurred in the last four decades. However, the development of new techniques has not resulted in $\mathrm{F}$ determination becoming simpler or more cost-effective. Some of the newer methods are expensive and complex and can only be used for certain types of samples [Clarkson et al., 2000].

In spite of significant discoveries made possible by early $\mathrm{F}$ analysis techniques, incorrect assumptions were made due to the inherent limitations of those initial methodologies. Good examples of this would be those studies which proposed that there were homeostatic mechanisms maintaining $\mathrm{F}$ levels in the body independent of the amount ingested [Singer and Armstrong, 1960] and those that supported the belief that the placenta acted as a partial barrier to the passage of $\mathrm{F}$ [Gedalia, 1970]. These erroneous conclusions were reached in part due to the inability of available techniques to measure ionic fluoride instead of total fluoride.

At present, the most frequently used techniques for $\mathrm{F}$ analysis of samples are gas chromatography [Fresen, 1968], ion chromatography [Michigami et al., 1993; Inoue et al., 1995; Perring and Bourqui, 2002] and the F ion-selective electrode [Frant and Ross, 1966; Gron et al., 1968; Muehlemann, 1969; Iizuka et al., 1970; Clark and Dowdell, 1973; Fagioli et al., 1984; Kissa, 1987; Itai and Tsunoda, 2001; Malde et al., 2001]. The F ion-selective electrode consists of a sensing element bonded into an epoxy body. The F ion-selective electrode produces a potential across a lanthanum fluoride $\left(\mathrm{LaF}_{3}\right)$ solid ion exchange phase. The measured potential corresponding to the activity of fluoride ions in solution is described by the Nernst equation [Nernst and Schönflies, 1895].

The different approaches currently employed to determine total $\mathrm{F}$ may require pretreatment of samples, separation and concentration of $\mathrm{F}$, actual measurement of $\mathrm{F}$ ions, calculations of final concentrations per unit of samples, and presentation of the data. Researchers have conducted these necessary steps using many different approaches.

Currently available $\mathrm{F}$ measurement techniques are not standardized and a universal standard method for F determination has not been established [Clarkson et al., 2000]. Although a variety of techniques are available, none have been accepted for universal use. The current project aimed to review existing analytical techniques for $\mathrm{F}$ analysis and identify inconsistencies in their use, between laboratories dedicated to $\mathrm{F}$ analysis for dental research, in order to develop a universal gold standard method.

\section{Materials and Methods}

Nine laboratories with an established track record of publications in the area of $\mathrm{F}$ analysis for dental research and a history of previous collaborations participated in this effort. In order to use biological samples, Institutional Review Board (IRB) and Institutional Animal Care and Use Committee (IACUC) approvals were obtained at Indiana University (the coordinating site) prior to initiation of the study. The study was undertaken in three phases. In phase 1 comparisons of currently used techniques were conducted. In phase 2 , the techniques used by participating laboratories were reviewed and comparative tests conducted to resolve identified differences. In phase 3 the universal gold standard methods were developed and tested in a variety of samples.

\section{Phase 1}

In phase 1, all laboratories analyzed a standardized set of biological and nonbiological samples, in order to obtain a preliminary measure of agreement. This initial sample set included: standard F solutions $(0.0132,0.02631,0.0526,0.2631$ and $0.5263 \mu \mathrm{mol}$ $\mathrm{F} / \mathrm{ml}$ ) prepared through the dilution of a commercially available standard fluoride solution $(0.1 \mathrm{~mol} / \mathrm{l} \mathrm{NaF}$, Orion Fisher Scientific Co., Itasca, Ill., USA), beverages (carbonated and noncarbonated, water- and dairy-based), food (homogenized for 1 and $10 \mathrm{~min}$ using a tissue homogenizer, single item and pooled meal-based samples), saliva (human, pooled and from individual donors), plasma, and urine (from healthy and systemically compromised donors). Each laboratory analyzed the samples, in duplicate (two aliquots of each sample were analyzed), using the methods they routinely used for $\mathrm{F}$ analysis according to sample type. All participating laboratories were asked to provide a description of their own methods. All of the laboratories basically used different modifications of two techniques for F determination: (1) direct analysis using a F ion-selective electrode (Orion No. 96-09 or 94-09; Fisher Scientific Co.) and a pH/ion meter (Orion No. 420A, 720A or EA940) was mainly used for standard solutions; (2) modifications of the hexamethyldisiloxane (HMDS; Sigma Chemical Co., St. Louis, Mo., USA) microdiffusion method of either Taves [1968] or Venkateswarlu [1977] were used for analysis of foods, beverages, urine, saliva, and plasma samples. Direct methods simply involved adding total ionic strength adjustment buffer solutions (TISAB, Orion, Thermo Electron Corp., USA) to the sample for the purpose of adjusting the $\mathrm{pH}$ and ionic strength of the standards and samples to the same values. In contrast, the diffusion methods extracted the $\mathrm{F}$ from the original sample and transferred it to a trapping solution of small volume so the F concentration in the solution that was finally analyzed was well above the limit of sensitivity of the electrode. Laboratories used this technique when the F in the sample was near or below the limit of sensitivity of the electrode or when the sample was not a liquid. A detailed review of the different standard operating procedures (SOP) used by the collaborating sites in phase 1 demonstrated that a range of different combinations of reagents and techniques were employed, regardless of whether a direct method or diffusion method was used.

\section{Phase 2}

In phase 2, inconsistencies in the use of direct and diffusion techniques among laboratories were identified. Comparative tests were conducted for both direct and diffusion methods and are 


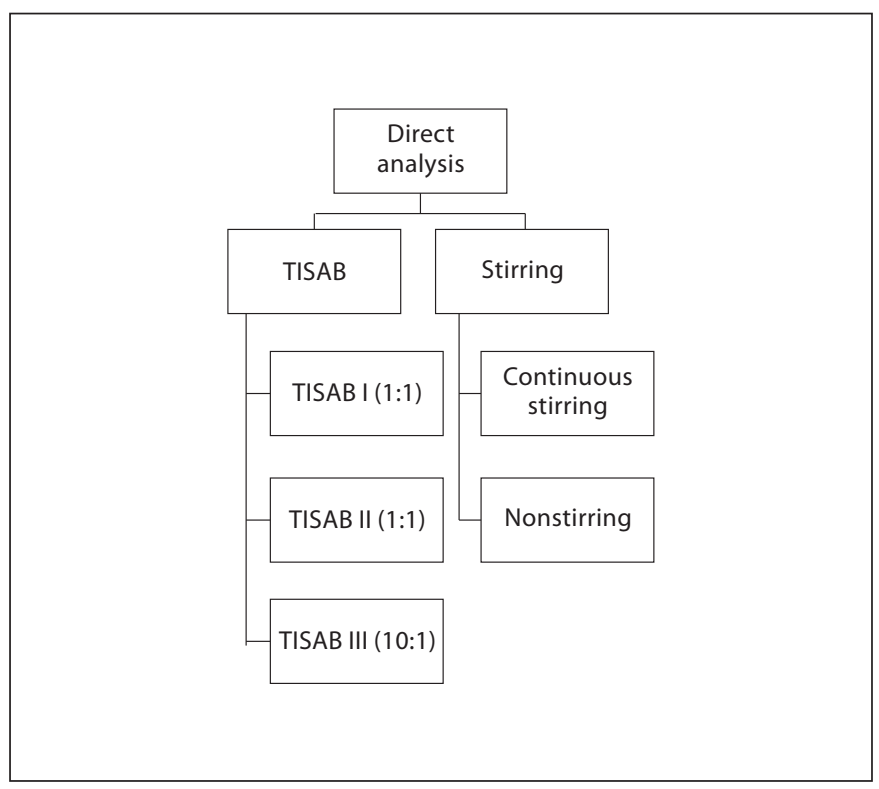

Fig. 1. Comparative tests performed for direct methods.

presented in figures 1-3. Factors such as the influence of stirring, sealing material used for the diffusion system, and choice of reagents and mathematical calculations to obtain concentrations from raw analytical data were tested. The use of a blank correction as suggested by Villa [1988] for samples with low F content was also investigated. Detailed information regarding the specific test(s) performed in this phase has been published elsewhere and is available as online supplementary material on the Karger website (www.karger.com/doi/10.1159/000321657).

Phase 3

In phase 3 of the development process, results from the tests in phase 2 were distributed to all laboratories and a plan was developed to resolve any differences in results and to identify preferred analytical procedures. Consensus SOPs to analyze F using the direct and diffusion methods were then developed and accepted by all laboratories. Once the agreed SOP was tested, modifications were proposed and tested for specific sample types and a consensus was reached as to the choice of method to be used based on sample type and objective of the analyses. For plasma, saliva and food samples, $0.2 \mathrm{~mol} / \mathrm{l}$ acetic acid and $0.15 \mathrm{~mol} / \mathrm{l}$ perchloric acid buffers with traps of $50 \mu \mathrm{l}$ of 0.075 and $0.05 \mathrm{~mol} / \mathrm{l}$ $\mathrm{NaOH}$ were tested. Additional testing using stimulated centrifuged and noncentrifuged saliva with the diffusion method was performed. The effect of pooling food samples, the consistency of the homogenate, and the size of the particles in food (quality of the homogenate) were assessed. For urine samples, sodium carbonate was added $\left(0.0094,0.0943\right.$ and $0.9434 \mu \mathrm{mol} \mathrm{Na} \mathrm{CO}_{3}^{-} / \mathrm{ml}$ urine) to assess its possible effects on fluoride measurements. For urine, selected samples with a confirmed presence of proteins (due to systemic conditions present in the donors) were also analyzed for comparison. Carbonate was added while measuring with the direct method.

Gold Standard Methods for Fluoride Analysis

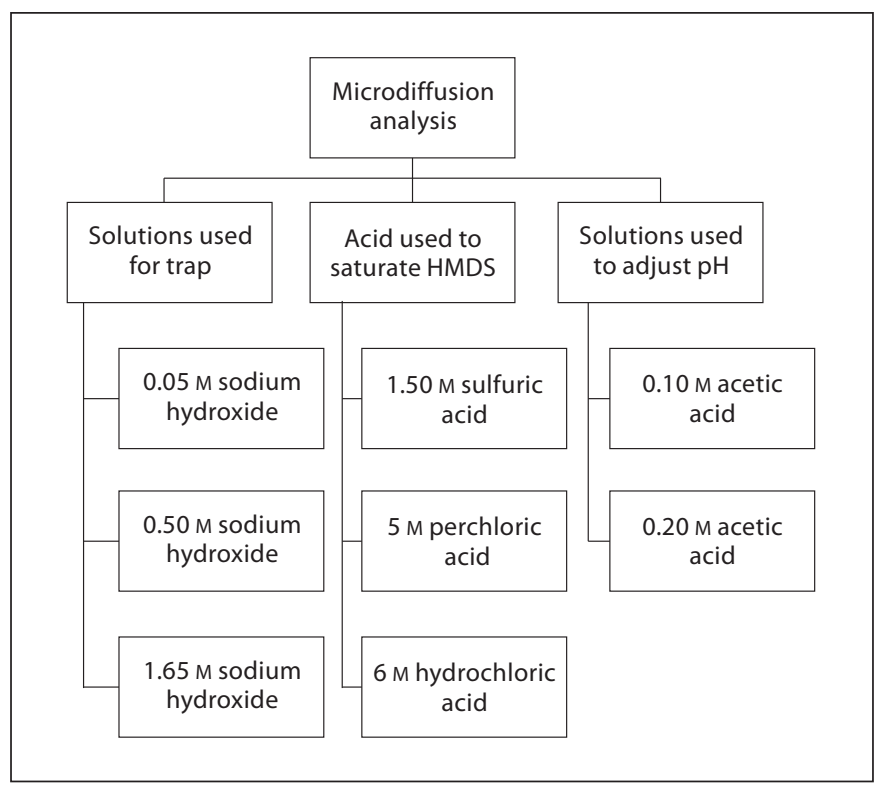

Fig. 2. Comparative tests performed for microdiffusion methods.

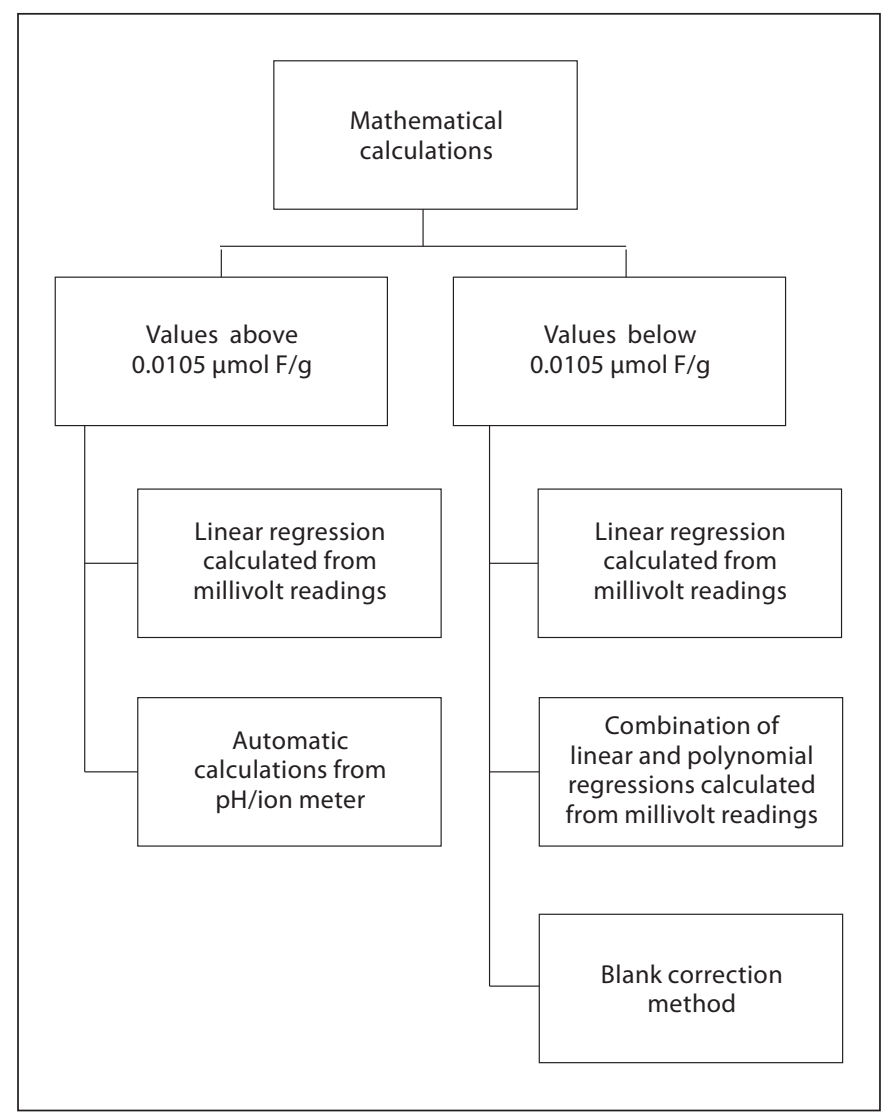

Fig. 3. Approaches used for mathematical calculations to obtain concentration values from raw analytical data. 
After testing, a final set of samples was distributed. These included 15 replicates of National Institute of Standards and Technology (NIST)-traceable certified reference material in aqueous solution $(0.0348 \pm 0.0005$ or $0.0332 \pm 0.0016 \mu \mathrm{mol} / \mathrm{ml}$ as $\mathrm{NaF})$. All laboratories analyzed the reference material using both the direct method and diffusion methods, following the SOPs previously developed and agreed in phase 2 and approved by all laboratories. In addition to the reference material, a set of standard $\mathrm{F}$ solutions and a set of samples similar to those initially distributed during phase 1 , containing beverages, foods, saliva, plasma, and urine were sent to each laboratory. Spiking, as recommended by Thompson et al. [1999] and Barwick and Ellison [1999], was used to assess recovery for this set of samples. Recovery of fluoride and precision was calculated according to ISO Guide 33 [2000]. Results of standard addition calculations were used to asses if specific matrices created interferences in the measurements of the fluoride added. Repeat analyses (two aliquots read the same day) were conducted by all laboratories using the two agreed SOPs. Fluoride concentration was measured by comparison with a standard curve. The curve standards were microdiffused at the same time as the samples and were read from lowest to highest concentration. Five points were used to construct a standard curve for values below $0.0105 \mu \mathrm{mol} \mathrm{F/g}$, while a minimum of three points were used to construct the curve for values above $0.0105 \mu \mathrm{mol} \mathrm{F} / \mathrm{g}$. The standard curve was constructed by creating a linearized plot of the electrode potential against the log of the activity of the samples read. Based on the Nernst equation, the theoretical slope should be $-59.2 \mathrm{mV} / \mathrm{decade}$ at $25^{\circ} \mathrm{C}$ (the value of the Nernst slope is temperature-dependent).

\section{Statistical Analysis}

Sample size calculations for phase 2 were based on the precision of the estimate of the intraclass correlation coefficient (ICC). In preliminary data, even without standardization methods, most of the ICC estimates were at least 0.65 . Using Fisher's transformation [Donner and Wells, 1986], it was estimated that 20 samples were needed to calculate a $95 \%$ lower confidence bound on the ICC values within a $5.6 \%$ difference. An ICC less than 0.70 was considered inadequate agreement and would have required additional standardization among laboratories.

Coefficients of variation (CVs) were calculated for comparison of results of samples analyzed in phases 1 and 2, for which there was not a certified, known value and were used as a measurement of relative precision. The amount of variation within and between laboratories was estimated using a random effects Analysis of Variance (ANOVA) model. Tests for normality of distribution and homogeneity of variance were conducted before performing analysis of variance. The ICCs were estimated from an ANOVA model using only the first replicate from each laboratory. The entire dataset including replicates was used to determine if there were statistically significant differences among the nine laboratories. The overall $\mathrm{F}$ test from the mixed effect ANOVA model was used to test the significance of the laboratory effect. Bland and Altman [1999] plots were constructed to assess relationships between differences and the average measurements assessed for any systematic bias between pairs of laboratories. Pairwise comparisons among the laboratories were also performed using a TukeyKramer adjustment for multiple comparisons. Limits of detection for pairwise comparisons were determined using Bland and Altman [1999] statistics.
Precision testing of the agreed upon methods was designed using the ISO Guide 32: Calibration in Analytical Chemistry and Use of Certified Reference Materials [ISO, 1997] and the NIST Special Publication 829: Use of NIST Standard Reference Materials for Decision on Performance of Analytical Chemical Methods and Laboratories [Becker et al., 1992]. To test the precision of the agreed methods, reagents and techniques for analysis of specific samples, the estimation of variance components, the interlaboratory correlation coefficients, precision, trueness, and bias were calculated for the results of the second common series of sample analyses. Precision was defined as the closeness of agreements between independent test results obtained under our agreed protocol for the direct method. Using a goal of a required withinlaboratory precision of $5 \%$, the estimated standard deviation would need to exceed $0.0083 \mu \mathrm{mol} \mathrm{F} / \mathrm{ml}$ for the reference material with a true value of $0.0332 \pm 0.0016 \mu \mathrm{mol} \mathrm{F} / \mathrm{ml}$ used for the direct methods technique and $0.0085 \mu \mathrm{mol} \mathrm{F} / \mathrm{ml}$ for the reference material with a true value of $0.0348 \pm 0.0005 \mu \mathrm{mol} \mathrm{F} / \mathrm{ml}$ used for the microdiffusion technique, to conclude that the measurement was not as precise as required.

Trueness was defined as the closeness of agreement between the average values obtained from a large series of test results and the true value of the reference material. The trueness of the measurement process was assessed based on confidence Intervals that used both the within- and between-laboratory error terms. This is a more conservative (wider) interval than the traditional interval for a mean value. Additionally, pairwise comparisons among the laboratories were then performed using a Tukey-Kramer adjustment for multiple comparisons.

\section{Results}

\section{Phase 1}

Results obtained from the initial set of analyses demonstrated that there was no consensus regarding the choice of techniques for different types of samples. Standard solutions were directly analyzed by all laboratories using a combination F ion-selective electrode and a pH/ ion meter. Food and plasma samples were uniformly analyzed by diffusion; however, there was no consensus on the method of choice for urine, saliva or beverage samples, which were analyzed using either the direct or the diffusion method. In addition, saliva samples were analyzed with and without prior centrifugation.

For standard F solutions, when the results obtained from each laboratory were compared, the differences among the laboratories for the overall data set were not statistically significant. However, tendencies were detected in the results obtained. Table 1 presents results of these analyses. Bland-Altman plots demonstrated that the differences in percentage recoveries were larger for the lowest concentration standard $(0.0132 \mu \mathrm{mol} \mathrm{F} / \mathrm{ml})$. Minimum percentage recoveries ranged from 76 to $98 \%$. Some 
Table 1. Summary statistics for analyses of fluoride standard solutions

\begin{tabular}{llll}
\hline $\begin{array}{l}\text { Target } \\
\text { concentration } \\
(\mu \mathrm{mol} \mathrm{F} / \mathrm{ml})\end{array}$ & $\begin{array}{l}\text { Mean difference } \\
\text { from target concen- } \\
\text { tration }(\mu \mathrm{mol} \mathrm{F} / \mathrm{ml})\end{array}$ & $\begin{array}{l}\text { SD } \\
(\mu \mathrm{mol} \mathrm{F} / \mathrm{ml})\end{array}$ & $\begin{array}{l}\text { Minimum } \\
\text { fluoride } \\
\text { recovery }(\%)\end{array}$ \\
\hline 0.0132 & 0.00005 & 0.00157 & 76 \\
0.0263 & 0.0005 & 0.00105 & 80 \\
0.0526 & 0.0005 & 0.00263 & 94 \\
0.2631 & 0.00005 & 0.00316 & 98 \\
0.5263 & 0.0037 & 0.0053 & 98 \\
\hline
\end{tabular}

$\mathrm{n}=24$ per laboratory. All nine laboratories analyzed the solutions using direct methods.

Table 2. Agreement among laboratories before and after use of agreed protocol

\begin{tabular}{|c|c|c|c|c|}
\hline \multirow[t]{2}{*}{ Sample analyzed } & \multirow{2}{*}{$\frac{\text { Before }}{\text { ICC }}$} & \multicolumn{3}{|l|}{ After } \\
\hline & & ICC & within-laboratory variance & between-laboratory variance \\
\hline Food & 0.61 & 0.79 & $0.042(0.204)$ & $0.013(0.115)$ \\
\hline Plasma & 0.51 & 0.82 & $0.000(0.004)$ & $0.000(0.009)$ \\
\hline Saliva & 0.72 & 0.90 & $0.047(0.218)$ & $0.001(0.034)$ \\
\hline Standard solutions (direct analysis) & 0.90 & 0.93 & $0.003(0.001)$ & $0.001(0.002)$ \\
\hline Standard solutions (diffusion analysis) & 0.89 & 0.90 & $0.003(0.001)$ & $0.001(0.003)$ \\
\hline Urine & 0.52 & 0.85 & $0.198(0.445)$ & $0.022(0.149)$ \\
\hline
\end{tabular}

$\mathrm{n}=15$ per laboratory. Standard deviations are given in parentheses.

laboratories consistently obtained higher or lower values when compared with other laboratories. Pairwise comparisons showed significant differences among several of the laboratories.

The results of the analyses obtained at the different laboratories were compared and CVs (\%) were calculated. The CVs, which in this case were a measure of relative precision, ranged from 11.48 to $201.86 \%$ with the higher CVs being observed for saliva, food, plasma and beverage samples, indicating large differences among laboratories and a clear need for standardization of procedures. ICCs for results of analysis of samples in phase 1 are presented in table 2 . When values were averaged by sample type, significant differences in analyzed $\mathrm{F}$ concentration were observed for urine and beverage samples, whereas for $\mathrm{F}$ standard samples the ICC was above 0.80 .

When the dataset was compared the differences in results obtained in each laboratory were close to statistical significance $(\mathrm{p}=0.0505)$, indicating possible differences between laboratories. Only in the case of urine samples was a statistically significant overall $\mathrm{p}$ value $(\mathrm{p}=0.01)$ found, indicating that in the participating laboratories the values obtained were significantly different.

\section{Phase 2}

Results of analysis demonstrated that no TISAB solution (I, II, III) consistently rendered higher or lower values for fluoride concentration when compared to the others. Results obtained while comparing stirring versus nonstirring during analysis showed no statistically significant differences (paired t test, $p=0.94$ ) for standard solutions. In contrast, for the beverage set, a statistically significant difference was observed between the samples that were stirred versus the samples that were not stirred (paired t test, $\mathrm{p}=0.04$ ). For the tests conducted for microdiffusion techniques, results from the tests using different combinations of reagents to analyze selected samples showed different percentages of $\mathrm{F}$ recovery and some of them were unacceptable for precision testing (table 3). Modifications to the agreed standard protocol for spe- 
Table 3. Mean F recovery (\%) for samples using different reagents

\begin{tabular}{|c|c|c|c|}
\hline $1 \mathrm{ml}$ acid + HMDS & $\begin{array}{l}\text { Trap NaOH } \\
(\mathrm{mol} / \mathrm{l} ; 50 \mu \mathrm{l})\end{array}$ & $\begin{array}{l}\text { Trap buffer } \\
(25 \mu \mathrm{l})\end{array}$ & $\begin{array}{l}\text { Mean fluoride recovery } \\
(\%)\end{array}$ \\
\hline $\mathrm{H}_{2} \mathrm{SO}_{4}(1.5 \mathrm{~mol} / \mathrm{l})$ & 0.05 & $\mathrm{CH}_{3} \mathrm{CO}_{2} \mathrm{H}(0.1 \mathrm{~mol} / \mathrm{l})$ & 96.38 \\
\hline $\mathrm{HCl}(6 \mathrm{~mol} / \mathrm{l})$ & 0.05 & $\mathrm{CH}_{3} \mathrm{CO}_{2} \mathrm{H}(0.1 \mathrm{~mol} / \mathrm{l})$ & 104.68 \\
\hline $\mathrm{H}_{2} \mathrm{SO}_{4}(1.5 \mathrm{~mol} / \mathrm{l})$ & 0.05 & $\mathrm{CH}_{3} \mathrm{CO}_{2} \mathrm{H}(0.2 \mathrm{~mol} / \mathrm{l})$ & 95.43 \\
\hline $\mathrm{HCl}(6 \mathrm{~mol} / \mathrm{l})$ & 0.05 & $\mathrm{HClO}_{4}(0.1 \mathrm{~mol} / \mathrm{l})$ & 94.80 \\
\hline $\mathrm{H}_{2} \mathrm{SO}_{4}(1.5 \mathrm{~mol} / \mathrm{l})$ & 0.05 & $\mathrm{HClO}_{4}(0.1 \mathrm{~mol} / \mathrm{l})$ & 94.12 \\
\hline $\mathrm{HCl}(6 \mathrm{~mol} / \mathrm{l})$ & 1.65 & $\mathrm{CH}_{3} \mathrm{CO}_{2} \mathrm{H} 0.66 \mathrm{~mol} / \mathrm{l}(40 \mu \mathrm{l})$ & 94.10 \\
\hline $\mathrm{HClO}_{4}(5 \mathrm{~mol} / \mathrm{l})$ & 0.50 & $\begin{array}{l}\mathrm{CH}_{3} \mathrm{CO}_{2} \mathrm{Na}(0.5 \mathrm{~mol} / \mathrm{l}-90 \mu \mathrm{l}) \\
\mathrm{CH}_{3} \mathrm{CO}_{2} \mathrm{H}(2.5 \mathrm{~mol} / \mathrm{l}-10 \mu \mathrm{l})\end{array}$ & 94.00 \\
\hline $\mathrm{HClO}_{4}(5 \mathrm{~mol} / \mathrm{l})$ & 0.05 & $\mathrm{CH}_{3} \mathrm{CO}_{2} \mathrm{H}(0.2 \mathrm{~mol} / \mathrm{l})$ & 92.10 \\
\hline $\mathrm{HClO}_{4}(5 \mathrm{~mol} / \mathrm{l})$ & 0.05 & $\mathrm{CH}_{3} \mathrm{CO}_{2} \mathrm{H}(0.1 \mathrm{~mol} / \mathrm{l})$ & $58.95^{\mathrm{a}}$ \\
\hline $\mathrm{HCl}(6 \mathrm{~mol} / \mathrm{l})$ & 0.50 & $\mathrm{HClO}_{4}(0.1 \mathrm{~mol} / \mathrm{l})$ & $271.82^{\mathrm{a}}$ \\
\hline $\mathrm{H}_{2} \mathrm{SO}_{4}(1.5 \mathrm{~mol} / \mathrm{l})$ & 0.50 & $\mathrm{HClO}_{4}(0.1 \mathrm{~mol} / \mathrm{l})$ & $764.12^{\mathrm{a}}$ \\
\hline
\end{tabular}

$\mathrm{n}=15$ analyzed by three laboratories. True value of reference material $=0.0348 \pm 0.0005 \mu \mathrm{mol} \mathrm{F} / \mathrm{ml}$.

${ }^{a}$ Unacceptable fluoride recovery based on NIST Special Publication 829 [Becker et al., 1992].

Table 4. Differences in mean ( \pm SD) values among laboratories (in $\mu \mathrm{mol} \mathrm{F/ml} \mathrm{or} \mathrm{g)} \mathrm{before} \mathrm{and} \mathrm{after} \mathrm{use} \mathrm{of} \mathrm{agreed} \mathrm{protocol}$

\begin{tabular}{|c|c|c|c|c|c|c|c|c|c|c|c|c|c|c|c|c|}
\hline \multirow{3}{*}{$\begin{array}{l}\text { Labo- } \\
\text { ratory }\end{array}$} & \multicolumn{4}{|l|}{ Plasma } & \multicolumn{4}{|l|}{ Food } & \multicolumn{4}{|l|}{ Saliva } & \multicolumn{4}{|l|}{ Urine } \\
\hline & \multicolumn{2}{|l|}{ before } & \multicolumn{2}{|l|}{ after } & \multicolumn{2}{|l|}{ before } & \multicolumn{2}{|l|}{ after } & \multicolumn{2}{|l|}{ before } & \multicolumn{2}{|l|}{ after } & \multicolumn{2}{|l|}{ before } & \multicolumn{2}{|l|}{ after } \\
\hline & mean & SD & mean & SD & mean & SD & mean & $\mathrm{SD}$ & mean & $\mathrm{SD}$ & mean & SD & mean & SD & mean & $\mathrm{SD}$ \\
\hline 1 & 0.0047 & $5 \mathrm{E}-04$ & 0.005 & 0.0005 & 0.0432 & 0.046 & 0.044 & 0.011 & 0.1852 & 0.0817 & 0.187 & 0.0735 & 0.225 & 0.0284 & 0.2237 & 0.026 \\
\hline 2 & 0.0026 & $5 \mathrm{E}-04$ & 0.005 & 0.0005 & 0.0426 & 0.043 & 0.043 & 0.028 & 0.2027 & 0.0552 & 0.191 & 0.0725 & 0.216 & 0.0432 & 0.2227 & 0.026 \\
\hline 3 & 0.0042 & $5 \mathrm{E}-04$ & 0.005 & 0.00105 & 0.0363 & 0.034 & 0.043 & 0.01 & 0.1963 & 0.1482 & 0.191 & 0.0991 & 0.216 & 0.0495 & 0.2316 & 0.025 \\
\hline 4 & 0.0042 & $5 \mathrm{E}-04$ & 0.004 & 0.0005 & 0.035 & 0.035 & 0.041 & 0.019 & 0.0516 & 0.1057 & 0.193 & 0.1083 & 0.229 & 0.0679 & 0.24 & 0.036 \\
\hline 5 & 0.0089 & $5 \mathrm{E}-04$ & 0.004 & 0.0005 & 0.0358 & 0.034 & 0.042 & 0.011 & 0.2027 & 0.0715 & 0.189 & 0.0793 & 0.226 & 0.0421 & 0.2321 & 0.022 \\
\hline 6 & 0.0037 & $5 \mathrm{E}-04$ & 0.004 & 0.0005 & 0.0384 & 0.02 & 0.042 & 0.003 & 0.1832 & 0.0636 & 0.19 & 0.0817 & 0.193 & 0.0405 & 0.2352 & 0.023 \\
\hline 7 & 0.0016 & $5 \mathrm{E}-04$ & 0.004 & 0.0005 & 0.0205 & 0.035 & 0.038 & 0.052 & 0.2084 & 0.064 & 0.194 & 0.0552 & 0.213 & 0.0347 & 0.2158 & 0.018 \\
\hline 8 & 0.0026 & $5 \mathrm{E}-04$ & 0.004 & 0.0005 & 0.0447 & 0.002 & 0.043 & 0.009 & 0.1753 & 0.1816 & 0.192 & 0.1482 & 0.221 & 0.0316 & 0.2153 & 0.02 \\
\hline 9 & 0.0037 & $5 \mathrm{E}-04$ & 0.004 & 0.0005 & 0.0416 & 0.043 & 0.043 & 0.02 & 0.0584 & 0.0131 & 0.192 & 0.1057 & 0.218 & 0.0326 & 0.2279 & 0.022 \\
\hline
\end{tabular}

$\mathrm{n}=15$ per laboratory.

cific sample types, as well as recommendations for the appropriate method based on sample type and objective of the analyses, are presented in figure 4 . For urine, statistically significant differences were obtained when proteins were present in the sample if direct analysis was used but not for carbonate additions. Significant differences were also observed for saliva samples based on pretreatment (centrifuged vs. noncentrifuged) for both direct and diffusion analysis. Finally, pooling, homogenizing or particle size for food samples had no significant effect on analyzed $\mathrm{F}$ concentration.
When comparing different formulas used to obtain values from raw data for both direct and microdiffusion techniques, the values produced by linear calibration and the $\mathrm{pH} /$ ion meter were similar. There were no statistically significant differences between the values calculated using a linear regression model and those obtained using a combination of linear and polynomial regressions for values above $0.0105 \mu \mathrm{mol} \mathrm{F} / \mathrm{ml}$. The correlation values between the measured concentrations obtained using the standard curves and the target concentrations were similar for all regressions. A combination of a two-term poly- 


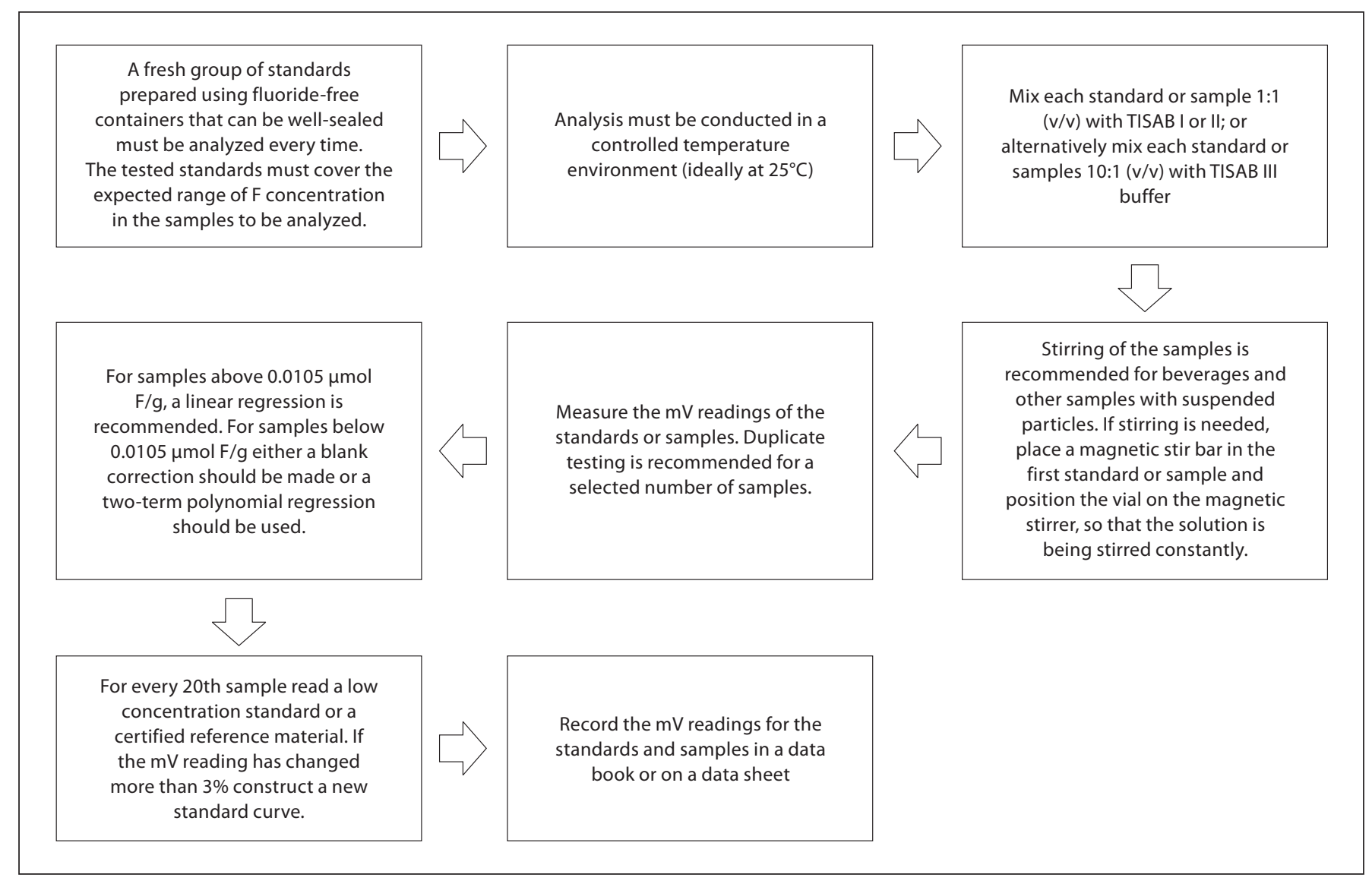

Fig. 4. Recommendations for the direct method.

nomial and linear regression for values below and above $0.0105 \mu \mathrm{mol} \mathrm{F} / \mathrm{ml}$, respectively, produced the results closest to the theoretical F concentration in the samples. Results obtained incorporating a blank correction using a linear calculation demonstrated its usefulness for samples between 0.00105 and $0.0105 \mu \mathrm{mol} \mathrm{F} / \mathrm{ml}$.

\section{Phase 3}

Using the agreed protocol for direct $\mathrm{F}$ analysis for the reference material, ICC was 0.93 , showing improved agreement among the laboratories (tables 2, 4). The results of sample analyses presented in table 4 demonstrate that both the intra- and interlaboratory variation decreased, as indicated by the smaller standard deviations. The overall $\mathrm{F}$ test from the mixed effects ANOVA model continued to show a statistically significant laboratory effect $(\mathrm{p}<0.0001)$. None of the laboratories exceeded the set variance level of $0.0084 \mu \mathrm{mol} \mathrm{F} / \mathrm{ml}$, therefore, no laboratory failed the precision test or the trueness test using the agreed protocol for the direct method. For the diffusion analysis, the ICC was 0.90 , showing significant agreement among the laboratories. Using a goal of required within-laboratory precision of $5 \%$, the estimated standard deviation would need to exceed $0.0085 \mu \mathrm{mol}$ $\mathrm{F} / \mathrm{ml}$ to conclude that the measurement was not as precise as required. Based on the analyses recommended by ISO, the precision was acceptable overall and for each laboratory. The overall trueness was also acceptable.

Bland-Altman plots demonstrated that the differences in percentage recoveries no longer showed a concentration-dependent bias. Minimum percentage recoveries ranged from 83 to $99 \%$, also demonstrating an improvement from results obtained in phase 1 . Mean percentage recoveries for samples below $0.0526 \mu \mathrm{mol} \mathrm{F} / \mathrm{ml}$, for both the direct and microdiffusion techniques, ranged from a $78 \%$ recovery when laboratories used their routine methods for $\mathrm{F}$ analysis to an $89.05 \%$ recovery once the standardized SOP was employed. 


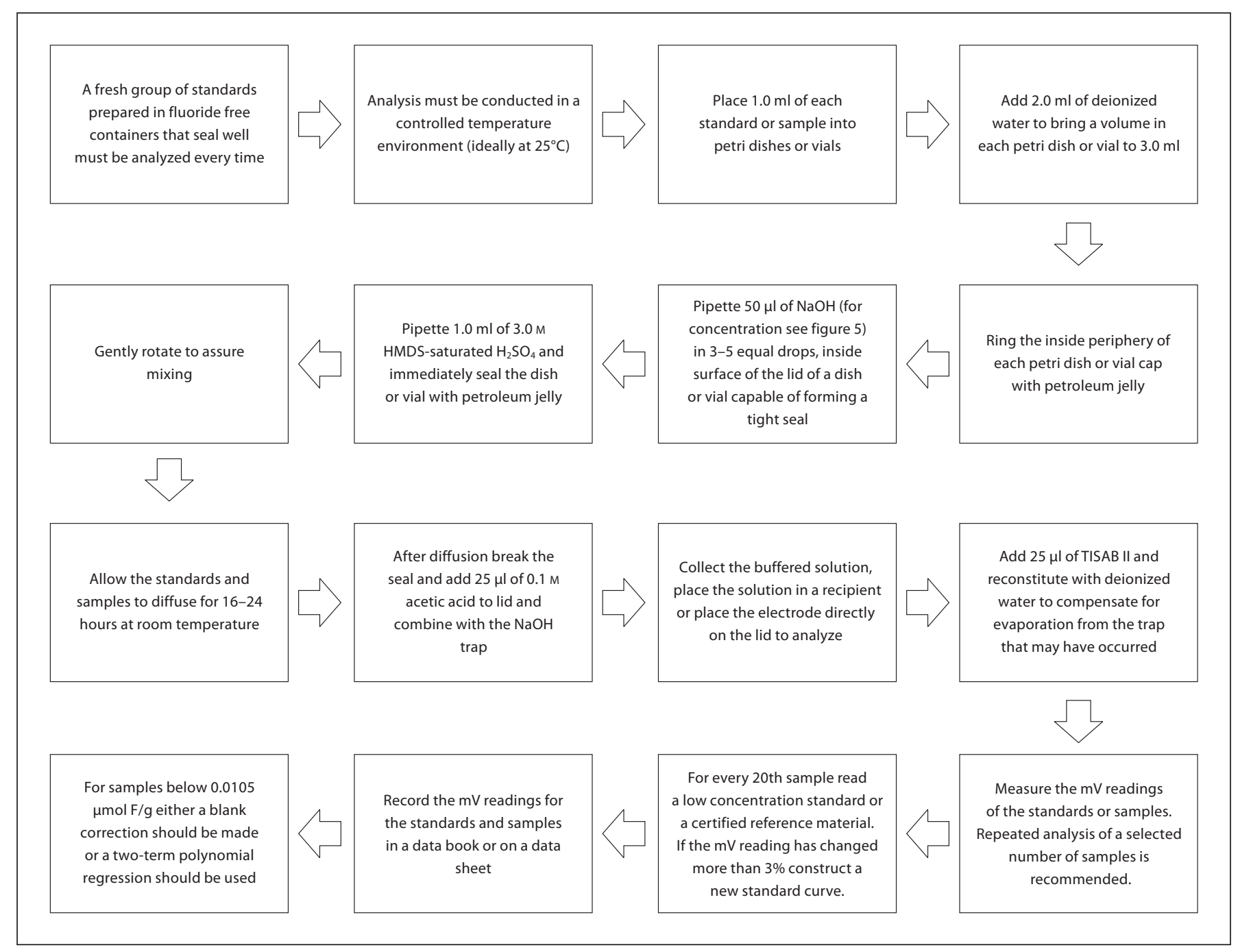

Fig. 5. Recommendations for the microdiffusion method.

\section{Discussion}

Initial results of this study demonstrated that there was no consensus regarding the choice of analytical techniques for different types of samples used in the participating laboratories. Although for several types of samples, the results of the fluoride analyses were similar, statistically significant differences were found for others. These percentage differences appeared to be larger for samples with lower concentrations of $\mathrm{F}$ and for certain types of samples, such as saliva, urine and beverages. The results of the present study are consistent with those of Lopez and Navia [1988], who developed a method to determine free $\mathrm{F}$ using acid hydrolysis. In their study, the initial results also showed that the largest standard deviations were mostly found in the lower F concentration standards.

In the current study, the ICC among the participating laboratories was excellent for standard F solutions; however, some trends in the results were detected. Some laboratories consistently obtained higher or lower values when comparisons were made, while pairwise comparisons showed differences among several laboratories. These results are also consistent with those of Mthethwa and du Plessis [2005], who compared the fluoride concentration of water reported by nine laboratories and the laboratory at the South African Bureau of Standards in light of the implementation of water fluoridation in South 


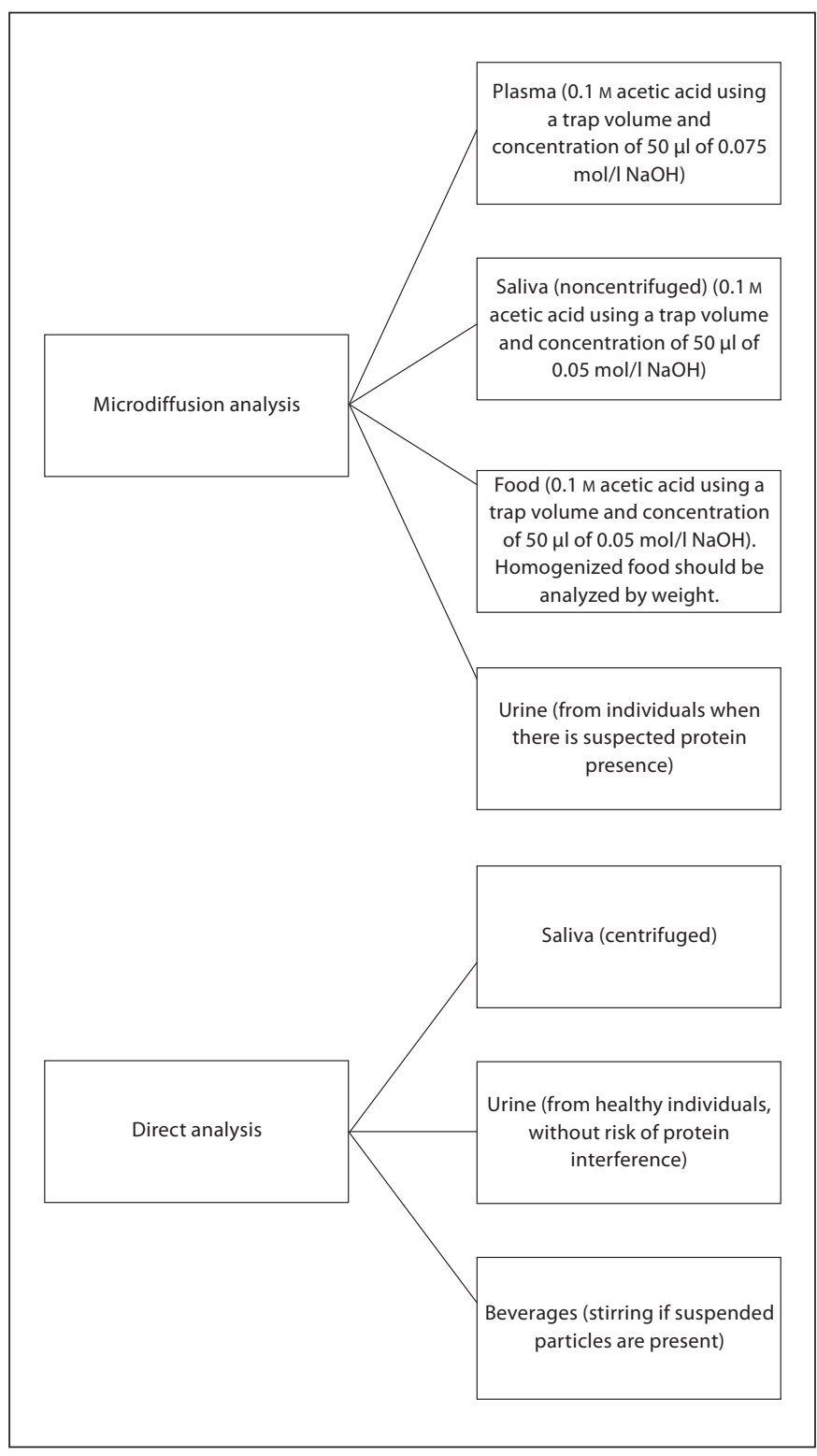

Fig. 6. Sample-specific recommendations.

Africa. Their results also showed that several different methods for the determination of fluoride were used and demonstrated that some laboratories were consistently higher or lower than others. They concluded that South African laboratories were not accurate enough in determining fluoride concentrations to ensure that the process of water fluoridation would be safe and recommended that laboratories check their procedures and participate in standardization exercises.

Gold Standard Methods for Fluoride Analysis
In the present study, ion-selective electrode-based, potentiometric methods were selected as the technology of choice for the standardization of $\mathrm{F}$ analytical methods since those are most ubiquitously used. It was most important to improve precision/trueness and to ensure standardization for improvements in dental public health in relation to $\mathrm{F}$ exposure. When making determinations of $\mathrm{F}$ concentrations, the results of previous comparative studies including the nine laboratories' previous work were taken into consideration and, additionally, it was considered that the ion-selective electrode-based methods are easily accessible, better suited for field studies and have an acceptable lower detection limit.

Based on the F analysis assessment, recommendations for direct and microdiffusion methods for measurements under the F ion electrode were developed. These recommendations are presented in figures $4-6$. For the direct method (fig. 4), stirring is only recommended for samples that have suspended particles (for example, some beverages).

For the microdiffusion method (fig. 5), the recommendation regarding which acids can be added to the sodium hydroxide trap to form a buffered solution was based on the fact that, although the efficiency of the acids was similar, acetic acid appeared to be the most suitable based on availability, cost and handling. The recommendation that sulfuric acid is used for HMDS saturation is due to the fact that it produced the best recoveries. When the results were analyzed using the additional modifications to the base microdiffusion technique, it was also observed that these varied depending on the seal of the system. Based on these results and the ease of in-sealing, petroleum jelly is preferred to the use of Parafilm. Results of analysis for specific types of samples showed that the concentration of the sodium hydroxide trap should vary depending on the initial concentration of the samples to be analyzed. Other sample-specific recommendations were made based on the pretreatment of choice or sample type (for example, centrifugation of saliva, or presence of proteins in urine), recognizing that the objectives of the investigations should also influence the choice of pretreatment or type of sample collected for $\mathrm{F}$ analysis (fig. 6).

The results of this study demonstrate that the development and use of standardized protocols for $\mathrm{F}$ analysis significantly increased fluoride recovery and resulted in very precise and true values, as measured by the analysis of a certified reference material. These findings are in agreement with the results of an active interlaboratory comparison program for several toxic substances in blood 
and urine, including fluoride, described by Weber [1988]. In his description, he stated that participation in the program allowed laboratories to improve or maintain the accuracy of their analytical work by periodically comparing their results.

In conclusion, the steps taken to develop gold standard methods for $\mathrm{F}$ analysis described here have the following implications: standardization of direct and diffusion techniques will benefit all studies requiring the use of standard F solutions and those specifically dealing with $\mathrm{F}$ ingestion and toxicity and the determination of $\mathrm{F}$ content in different matrices. The standardization of techniques will also benefit public health policymakers in countries using community fluoridation, to determine the ideal methods to conduct monitoring.

\section{Acknowledgments}

The authors would like to thank Mrs. S. Kelly for her skillful help in IRB application, Mr. T. Ewing for his assistance with the IACUC application, and Ms. C. Buckley for her technical support. Study supported by a National Institute of Dental and Craniofacial Research grant (NIDCR grant R21 DE 14716-1).

Dr. George K. Stookey is President/CEO of Therametric Technologies, Inc., Indianapolis, Ind., USA. Dr. Jordi Margineda is Sales Specialist in PCR, Hematology and Coagulation for Roche Diagnostics, SL, Barcelona, Spain.

\section{Disclosure Statement}

No potential conflicts of interest are reported for any of the authors.

\section{References}

Barwick V, Ellison S: Measurement uncertainty: approaches to the evaluation of uncertainties associated with recovery. Analyst 1999;124: 981-990.

Becker D, Christensen R, Currie L, Diamondstone B, Eberhardt KR, Gills T, Hertz H, Klouda G, Moody J, Parris R, Schaffer R, Steel E, Taylor J, Watters R, Zeisler R (Center for Analytical Chemistry Quality Assurance Task Group): Use of NIST Standard Reference Materials for Decisions on Performance of Analytical Chemical Methods and Laboratories. Gaithersburg, NIST Special Publication 829, 1992

Bland JM, Altman DG: Measuring agreement in method comparison studies. Stat Methods Med Res 1999;8:135-160.

-Clark NG, Dowdell LR: Radiotelemetric method for the study of $\mathrm{pH}$ and $\mathrm{F}$ ion concentration in dental plaque and saliva. Med Biol Eng 1973;11:159-163.

-Clarkson JJ, Hardwick K, Barmes D: Research needs workshop report: international collaborative research on fluorides. J Dent Res 2000;79:893-904.

-Donner A, Wells G: A comparison of confidence interval methods for the intraclass correlation coefficient. Biometrics 1986;42:401412; erratum in: Biometrics 1986;42:1009.

Fagioli F, Suttina MG, Nonato M, Calura G: Use of a fluoride ion-sensitive electrode for the determination of fluorides in saliva using the Gran method (in Italian). Riv Ital Stomatol 1984;53:603-609.

-Frant MS, Ross JW Jr: Electrode for sensing fluoride ion activity in solution. Science 1966; 154:1553-1555.

-Fresen JA: Determination of fluoride in biological material by gas chromatography. Pharm Tijdschr Belgie 1968;45:177-179.
Gedalia I: Distribution in placenta and fetus; in Fluorides and Human Health. Monograph Series. Geneva, WHO, 1970, No 59.

Gron P, McCann HG, Brudevold F: The direct determination of fluoride in human saliva by a fluoride electrode: fluoride levels in parotid saliva after ingestion of single doses of sodium fluoride. Arch Oral Biol 1968;13:203-213.

Iizuka Y, Akiba C, Nakayama Y: Evaluation and development of rapid and simple techniques for the determinations of fluorine in water, saliva, urine, and tooth powder by a fluoride electrode. Bull Tokyo Dent Coll 1970;11:155-168.

- Inoue Y, Tajima I, Sakai T: Determination of fluoride by ion chromatography using solidphase extraction with complexation. Kogyo Yosui 1995;445 28-33.

ISO Guide 32:Calibration in Analytical Chemistry and Use of Certified Reference Materials. Geneva, ISO, 1997.

ISO Guide 33:Uses of Certified Reference Materials, ed 2. Geneva, ISO, 2000.

Itai K, Tsunoda H: Highly sensitive and rapid method for determination of fluoride ion concentrations in serum and urine flow injection analysis with a fluoride ion-selective electrode. Clin Chim Acta 2001;308:163-171.

Kissa E: Determination of inorganic fluoride in blood with a fluoride ion-selective electrode. Clin Chem 1987;33:253-255.

Lopez H, Navia JM: A method to assay fluoride in foods, beverages, and diets. Caries Res 1988;22:210-216.

- Malde MK, Bjorvatn K, Julshamn K: Determination of fluoride in food by the use of alkali fusion and fluoride ion-selective electrode. Food Chem 2001;73:373-379.

Michigami Y, Kuroda Y, Ueda K, Yamamoto Y: Determination of urinary fluoride by ion chromatography. Anal Chim Acta 1993;274 299-302.
Mthethwa MT, du Plessis JB: A comparison of results of fluoride determinations by different laboratories. SADJ 2005;60:238-240.

Muehlemann HR: Oral pH- and fluoride ion telemetry. Annu Meet Am Inst Oral Biol 1969; 26:121-133.

Nernst W, Schönflies A: Einführung in die mathematische Behandlung der Naturwissenschaften. Kurzgefasstes Lehrbuch der Differential- und Integralrechnung mit besonderer Berücksichtigung der Chemie. Munich, 1895.

- Perring L, Bourqui B: An alternative method for fluoride determination by ion chromatography using post-column reaction. Mineral Laboratory, Quality and Safety Assurance Department, Nestlé Research Centre, Lausanne, Switzerland/American Laboratory, Shelton, Conn, United States 2002;34:28-30.

- Singer L, Armstrong WD: Regulation of human plasma fluoride concentration. J Appl Physiol 1960;15:508-510.

Taves DR: Separation of fluoride by rapid diffusion using hexamethyldisiloxane. Talanta 1968;15:969-974.

- Thompson M, Ellison SLR, Fajgelj A, Willetts P, Wood R: Harmonized guidelines for the use of recovery information in analytical measurement. Pure Appl Chem 1999;71:337-348.

Venkateswarlu P: Determination of fluorine in biological materials. Methods Biochem Anal 1977;24:93-201.

-Venkateswarlu P: Evaluation of analytical methods for fluorine in biological materials. J Dent Res 1990;69:514-521.

-Villa A: A rapid method for determining very low fluoride concentrations using an ion-selective electrode. Analyst 1988;113:1299-1303.

-Weber JP: An interlaboratory comparison programme for several toxic substances in blood and urine. Sci Total Environ 1988;71:111-123. 